\title{
Potassium Binders
}

\author{
Agnieszka Tycinska1, Ewa A Jankowska ${ }^{2,3}$
}

1. Department of Cardiology, Medical University of Bialystok, Poland

2. Department of Heart Diseases, Wroclaw Medical University, Poland

3. Centre for Heart Diseases, University Hospital, Wrocław, Poland

\section{Corresponding author:}

Ewa A Jankowska, Department of Heart Diseases, Wroclaw Medical University and Centre for Heart Diseases, University Hospital in Wroclaw, Poland.

Email: ewa.jankowska@umed.wroc.pl

\begin{abstract}
Hyperkalaemia is common in treated HF, especially if on RAAS inhibitor drugs and in the presence of impaired renal function. The signs and/or symptoms of hyperkalaemia include weakness, fatigue, and/or paralysis, nausea and constipation and bradyarrhythmias. ECG changes include peaked T waves, prolonged PR interval, wide QRS complex duration, the loss of P waves, and finally a sine-wave pattern. Emergency severe hyperkalaemia treatment to counteract its negative impacts includes using insulin infusion with glucose, beta-agonists (e.g. salbutamol) or $8.4 \%$ sodium bicarbonate and augmenting potassium removal from the body using cation exchange resins, loop diuretics or dialysis. Two newer agents have been approved for the treatment of hyperkalaemia ZS-9 and patiromer and these two agents are promising agents in the management of hyperkalaemia in the setting of HF, with the need for trials to prove their role in this setting, and whether they can safely allow RAASi drugs to be used at their recommended doses without the risk of hyperkalaemia.
\end{abstract}

Keywords: heart failure; potassium; hyperkalaemia; patiromer; ZS-9

Citation: $\quad$ Tycinska A and Jankowska, EA. Potassium Binders. International Cardiovascular Forum Journal. 2019;18:27-30. DOI: 10.17987/icfj.v18i0.621

\section{Introduction}

Hyperkalaemia is a very common condition in cardiovascular patients. It can result from increased potassium intake, impaired distribution between the intracellular and extracellular spaces, and/or reduced renal excretion. Hyperkalaemia is particularly prevalent in patients older than 65 years with advanced chronic kidney disease (CKD), diabetes, and/or chronic heart failure. Hyperkalaemia has been classified into mild ( $\mathrm{K}+$ of $5.0-5.5 \mathrm{mEq} / \mathrm{L})$, moderate $(\mathrm{K}+$ of $5.5-6.0 \mathrm{mEq} / \mathrm{L})$ and severe $(\mathrm{K}>6.0 \mathrm{mEq} / \mathrm{L})$, which allows a better stratification of the risk for patients.[1]

The American Heart Association (AHA) defines hyperkalaemia, when serum potassium values exceed $5.0 \mathrm{mEq} / \mathrm{L}$, and the European Society of Cardiology (ESC) guidelines warn for caution over these values.[2,3] The optimal serum potassium value for patients with cardiovascular disease is considered to be betwen 4 and $5 \mathrm{mEq} / \mathrm{L}$.

\section{Epidemiology of hyperkalaemia}

Hyperkalaemia is rarely detected in a general population. Among patients hospitalized for any cause, the incidence of hyperkalaemia ranges between 1-10\%.[4] In a general population of patients (including about $10 \%$ of them with chronic kidney disease [CKD]), the prevalence of hyperkalaemia is estimated to be about $3 \%$ of all emergency room visits and of hospital admissions.[5,6,7]

In the contemporary era, the prevalence of hyperkalemia as well as the rate of hospitalizations due to hyperkalaemia is increasing, which is strongly related with the more widespread use of the renin-angiotensin-aldosterone system (RAAS) blockers.[8] In patients with heart failure (HF), the prevalence of hyperkalaemia depends on the severity of HF, the age of a patient, the presence of concomitant diseases (mainly: CKD and diabetes mellitus [DM]), as well as the use of other drugs, in particular RAAS blockers. The prevalence of hyperkalaemia in patients with HF increases to $5 \%$ with a concomitant dual RAAS blocker therapy, and rises to up to $10 \%$ in patients with accompanying CKD.[9,10]

While initiating or titrating the dose of drugs blocking the RAAS in patients with HF, it is crucial to assess the risk of hyperkalaemia, as many of these patients already have impaired potassium excretion, placing them at an increased risk, in particular the elderly and those with renal impairment or diabetes.[6,11,12] As the RAAS blockers are life-saving drugs in patients with HF, the inability of their clinical use or optimal up-titration the dose due to hyperkalaemia is a serious therapeutic barrier. Concerning the tolerability of medications used for the treatment of HF patients and the potential increased risk of hyperkalaemia, it is worthwhile to notice that the results of the PARADIGM-HF trial revealed in sacubitril/valsartan group the lower risk of hyperkalaemia as compared with the enalapril group.[13]

\section{Clinical entities favouring the development of hyperkalaemia in heart failure}

The pathophysiology of hyperkalaemia in patients with HF 


\begin{tabular}{|c|c|}
\hline Clinical entities & Mechanisms leading to hyperkalaemia \\
\hline \multirow{3}{*}{ CKD } & $\begin{array}{l}\text { impaired elimination - lower potassium } \\
\text { clearance }\end{array}$ \\
\hline & $\begin{array}{l}\text { tubulointerstitial dysfunction - lower tubular } \\
\text { potassium secretion }\end{array}$ \\
\hline & $\begin{array}{l}\text { metabolic acidosis - potassium shift from the } \\
\text { intracellular to the extracellular space }\end{array}$ \\
\hline \multirow[t]{2}{*}{ Diabetes type 2} & $\begin{array}{l}\text { insulin deficiency and hypertonicity - } \\
\text { diminished ability to shift potassium to the } \\
\text { intracellular space }\end{array}$ \\
\hline & $\begin{array}{l}\text { hyporeninemic hypoaldosteronism - } \\
\text { decreased tubular potassium secretion }\end{array}$ \\
\hline RAAS blockers & $\begin{array}{l}\text { decreased aldosterone in HF ; decreased } \\
\text { absorption of sodium in the distal tubules; } \\
\text { decreased potassium excretion }(\mathrm{Na}+/ \mathrm{K}+ \\
\text { pump) }\end{array}$ \\
\hline \multirow{3}{*}{$\begin{array}{l}\text { Other medications } \\
\text { used for HF } \\
\text { treatment }\end{array}$} & $\begin{array}{l}\text { beta- } 2 \text { receptor blockers - reduced renin } \\
\text { production and hampered potassium } \\
\text { redistribution to the intracellular space }\end{array}$ \\
\hline & heparin - reduced aldosterone production \\
\hline & digitalis glycosides - Na-K-ATPase inhibition \\
\hline \multicolumn{2}{|c|}{$\begin{array}{l}\text { CKD - chronic kidney disease; HF - heart failure; RAAS - renin- } \\
\text { angiotensin-aldosterone system. (Kovesdy CP. Updates in } \\
\text { hyperkalemia: Outcomes and therapeutic strategies. Rev Endocr } \\
\text { Metab Disord. } 2017 \text { March ; 18(1): 41-47.). }\end{array}$} \\
\hline
\end{tabular}

is complex. The key factors favouring the occurrence of hyperkalaemia are shown in Table 1.

There is no direct relationship between the occurrence and severity of clinical symptoms and the severity of hyperkalaemia. Indeed, most patients with hyperkalaemia are asymptomatic. Hyperkalaemia is usually discovered through the blood screening, and when diagnosed, additional investigations such as electrocardiograms are performed to determine the severity of its clinical consequences.

The signs or/and symptoms of hyperkalaemia result from the interference of potassium with neuromuscular systems including skeletal muscle (weakness, fatigue, and paralysis as results of the decrease of muscle strength), visceral smooth muscle (nausea and constipation) and finally myocardial muscle (additional contractions and bradyarrhythmias).[14] In the ECG, hyperkalaemia mainly affects the depolarization period, which translates into the following changes observed along with increasing serum potassium levels: peaked $T$ waves, prolonged $\mathrm{PR}$ interval, wide QRS complex duration, the loss of $\mathrm{P}$ waves, and finally a sine-wave pattern - a prognostically bad forerunner of impending ventricular fibrillation and asystole.[14]

\section{Treatment of hyperkalaemia in emergency conditions}

The main goal of acute or severe hyperkalaemia treatment is to counteract its negative impact on muscles (myocardial, skeletal and smooth muscles) by transferring potassium cations from the extracellular volume to the cells and/or removing them from the body, thus normalizing the serum potassium level without causing hypokalaemia. The intensification of intracellular potassium shift can be achieved by using insulin infusion with glucose, betaagonists (e.g. salbutamol) or $8.4 \%$ sodium bicarbonate. The augmented potassium removal from the body can be obtained using cation exchange resins, loop diuretics or dialysis.

\section{Approach to reduce the risk of hyperkalaemia when using the RAAS blockers}

In order to prevent or reduce the risk of hyperkalaemia in patients treated with RAAS blockers, it is necessary to implement some clinical efforts, including a regular assessment of renal function and the use of adequate diuretic doses, screening and correction of potential metabolic acidosis, discontinuation of other medications impairing renal potassium excretion (including nonsteroidal anti-inflammatory drugs), the initiation of RAAS blockers with low doses along with a careful monitoring of serum potassium and creatinine.[14]

\section{Potassium binding agents}

Current strategies for pharmaceutical treatment of hyperkalaemia resulting from CKD or drug-induced hyperkalaemia tend to use cation exchange resins. The first and the oldest substances (used for over 60 years) of this type is sodium polystyrene sulphonate (SPS).[15] When using this agent in emergency situations, it should be remembered that its onset of action is seen after several hours following oral administration.[16] The evidence supporting the clinical use of this drug is based on one study involving 32 patients with azotemia, showing a significant decrease of serum potassium level of $0.9 \mathrm{mEq} / \mathrm{L}$ within 24 hours.[17] Due to the lack of alternative methods, SPS has become the main and most widely used therapeutic agent for hyperkalaemia. It is an organic cation exchange resin, which exchanges potassium for sodium in the gastrointestinal (Gl) tract. The drug has important life threatening adverse side effects, including: colon injury and transmural necrosis [18] and hypernatremia.[19]

In recent years, two newer agents have been approved for the treatment of hyperkalaemia. The first one, sodium zirconium cyclosilicate (ZS-9), is an inorganic, non-absorbing, microporous compound, acting as a selective sodium-potassium cationite, which catches potassium ions in the GI tract. It is believed that micropores present in the molecule resemble physiological potassium channels, due to which the agent neither captures nor binds calcium or magnesium ions (as it occurs in the case of aforementioned polystyrene sulphonates). ZS-9 is not absorbed in the Gl tract, because of its insoluble properties. Thus, the agent is thought to be safe.[20]

ZS-9 was studied in 94 outpatients with HF treated with RAAS blockers (the HARMONIZE trial).[20,21] At first, all patients enrolled into the study received an open-label ZS-9 (three times per day for $48 \mathrm{~h}$ ), which reduced serum potassium to normal levels within 48 hours in the majority of subjects.[20] Then the drug was assessed in the subgroup of normokalaemic patients, where 3 doses (5, 10 and $15 \mathrm{~g}$ once daily) were similarly effective in lowering and maintaining potassium levels, despite the continuation of RAAS blockers.[20,21] Side effects, including peripheral oedema and mild hypokalaemia (potassium level 3.0 to $<3.5 \mathrm{mEq} / \mathrm{L}$ ) were observed only when higher doses of the agent were used and were very rare (oedema occurred in one, two, and five patients in the $5 \mathrm{~g}, 10 \mathrm{~g}$, and $15 \mathrm{~g}$ dose groups, respectively, and one patient in the placebo arm, and mild hypokalaemia 


\begin{tabular}{|c|c|c|}
\hline & Mechanism of action & Adverse effects \\
\hline SPS/CPS & $\begin{array}{l}\text { Removal } \\
\text { Onset: } 60-180 \text { mins } \\
\text { Duration: } 240-360 \\
\text { K reduction: } 0.5-1.0 \text { per } 1 \\
\text { g resin }\end{array}$ & $\begin{array}{l}\text { Nausea, } \\
\text { constipation, } \\
\text { diarrhea, paralytic } \\
\text { ileus, cecal } \\
\text { perforation, } \\
\text { hypercalcemia, } \\
\text { hypernatremia }\end{array}$ \\
\hline Hemodialysis & $\begin{array}{l}\text { Removal } \\
\text { Onset: }<10 \text { mins } \\
\text { Duration: }<60-180 \\
\text { K reduction }: 1.2-1.5 / \mathrm{h}\end{array}$ & $\begin{array}{l}\text { Hypokalaemia, } \\
\text { arrhythmias }\end{array}$ \\
\hline $\begin{array}{l}\text { Loop diuretic } \\
\text { (furosemide) }\end{array}$ & $\begin{array}{l}\text { Removal } \\
\text { Onset: Immediate } 15 \text { mins } \\
\text { Duration: } 120-180\end{array}$ & $\begin{array}{l}\text { Ototoxicity, } \\
\text { hypokalaemia, } \\
\text { nephrotoxicity }\end{array}$ \\
\hline $\begin{array}{l}\text { Insulin + } \\
\text { dextrose }\end{array}$ & $\begin{array}{l}\text { Translocation } \\
\text { Onset: }<15-30 \text { mins } \\
\text { Duration: } 240-360 \\
\text { K reduction: } 0.5-1.5 \mathrm{mEq} / \mathrm{L} \\
\text { (dose dependent) }\end{array}$ & $\begin{array}{l}\text { Hypoglycaemia, } \\
\text { hyperosmolarity, } \\
\text { volume overload }\end{array}$ \\
\hline $\begin{array}{l}\text { Beta- } \\
\text { adrenergic } \\
\text { agonists }\end{array}$ & $\begin{array}{l}\text { Translocation } \\
\text { Onset: } 3-5 \text { mins onset } \\
\text { Duration: } 1-4 \mathrm{~h} \\
\text { K reduction: } 1.6-1.7 / 2 \mathrm{~h} \\
\text { (salbutamol) }\end{array}$ & $\begin{array}{l}\text { Tremor, } \\
\text { tachycardia }\end{array}$ \\
\hline $\begin{array}{l}\text { Sodium } \\
\text { bicarbonate } \\
\text { (Only in } \\
\text { patients with } \\
\text { metabolic } \\
\text { acidosis - } \\
\text { bicarbonate } \\
<22 \text { mEq/L) }\end{array}$ & $\begin{array}{l}\text { Translocation (doubt effect) } \\
\text { Correction of acidosis } \\
\text { Onset: } 30-60 \text { mins (onset). } \\
\text { Duration: } 2-6 \text { h }\end{array}$ & $\begin{array}{l}\text { Hypernatremia, } \\
\text { volume } \\
\text { overload, tetany, } \\
\text { hypertension }\end{array}$ \\
\hline $\begin{array}{l}\text { Calcium } \\
\text { gluconate }\end{array}$ & $\begin{array}{l}\text { Translocation } \\
\text { Stabilise myocardium, } \\
\text { protect cardiomycytes } \\
\text { Onset: } 1-3 \text { mins } \\
\text { Duration: } 30-60 \text { mins } \\
\text { K reduction: } 0.5-1.5 \mathrm{mEq} / \mathrm{L}\end{array}$ & $\begin{array}{l}\text { Hypercalcemia, } \\
\text { tissue necrosis }\end{array}$ \\
\hline
\end{tabular}

$\mathrm{CPS}=$ calcium polystyrene sulfonate; $\mathrm{SPS}=$ sodium polystyrene sulfonate

occurred in one patient in the $10 \mathrm{~g}$ dose group and three patients in the $15 \mathrm{~g}$ dose group).[21] A currently ongoing trial with ZS-9 is recruiting patients with $\mathrm{HF}$ and high serum potassium $(>5.0$ $\mathrm{mEq} / \mathrm{L}$ ) to initiate and intensify the RAAS blockers (PRIORITIZE HF, ClinicalTrials.gov Identifier: NCT03532009).

The next drug is calcium patiromer - a safe, oral non-absorbable potassium-binding agent, approved by the FDA. It is a nonresorbable polymer with the ability to exchange cations in the GI lumen which, as a counter ion, contains a calcium-sorbitol complex.[8,22] Patiromer is a high-performance polymer with the main part of its action occurring in the distal part of the colon, where potassium concentration is the highest. Because of its low viscosity, the agent easily mixes with water or food, and a small amount of sorbitol per dose does not cause osmotic diarrhoea.[8,22] The late onset of patiromer action, about 7 hours after administration, classifies the agent as a drug for the treatment of chronic hyperkalaemia. In comparison to resins, calcium patiromer can be administered 1-2 times per day, and its side effects are much less pronounced.[22] The agent is of a particular importance for patients treated with RAAS blockers, allowing to add/optimize dosage of these drugs and reducing the risk of hyperkalaemia.

The PEARL-HF study included patients with HF (mean LVEF $40 \pm 12 \%)$ treated with spironolactone, randomized to either patiromer (originally named RLY5016) or placebo. After 28 days of therapy, in an active group hyperkalaemia $(\mathrm{K}+>5.5$ $\mathrm{mEq} / \mathrm{L}$ ) was present in $7 \%$ as compared to $25 \%$ in a placebo arm $(p<0.05)$. At the end of the treatment period, RLY5016 had significantly lowered serum potassium levels relative to placebo, with a difference between groups of $-0.45 \mathrm{mEq} / \mathrm{L}(p<0.001)$.[23] Consequently, more patients receiving RLY5016 were able to receive the $50 \mathrm{mg}$ dose of spironolactone without hyperkalaemia as compared to a placebo arm $(91 \%$ vs $74 \%, p=0.019)$. The results regarding the effective up-titration of spironolactone and hyperkalaemia prevention were similar in patients with $\mathrm{HF}$ with versus without concomitant kidney dysfunction (GFR $<60 \mathrm{~mL}$ min./1.73m3).[23] The drug was relatively well tolerated as the occurrence of mild side effects (bloating, diarrhoea, vomiting) was approximately 20\%.[24] However, more RLY5016-treated patients had hypokalaemia $(<3.5 \mathrm{mEq} / \mathrm{L})$ than placebo patients (6 versus $0 \%$, respectively), and significantly more RLY5016treated patients had serum potassium $<4.0 \mathrm{mEq} / \mathrm{L}$ than patients receiving placebo (47 vs. $10 \%$, respectively, $\mathrm{p}<0.001$ ). In addition, more patients in the RLY5016 group were able to have their spironolactone dose up-titrated as compared with patients in the placebo group (91 vs.74\%, $\mathrm{p}<0.05$ ).

In the OPAL-HK study, among patients with CKD taking RAAS inhibitors (RAASi), the most frequently reported side effects of patiromer (in up to $11 \%$ of patients) were those related to the Gl tract, such as constipation, bloating, and nausea.[25] In the AMETHYST-DN study, among patients with HF, diabetes, CKD, and hyperkalemia treated with ACE-I/ARBs, patiromer was well tolerated and effective in terms of decreasing potassium level.[26]

When patiromer binds potassium, it usually releases calcium. Calcium ions may be absorbed by the intestine, then excreted to the urine, bound to other anions or rebound to patiromer. The moderate increase of calcium urine excretion together with reduced magnesium urine secretion may increase the risk of calcium-containing kidney stones. On the other hand, calcium released from patiromer in the small bowel may act as a phosphate binder, which could be useful for patients with CKD requiring phosphate-binding agents.

Due to its mechanism of action, patiromer may interacts with numerous drugs, reducing their the bioavailability. Therefore, the FDA has recommended to administer patiromer 6 hours prior to or after the administration of other drugs.[8]

Adverse effects of calcium patiromer are not serious or potentially life-threatening and mainly concern Gl disorders such as constipation, diarrhoea (occurring in $5 \%$ and $3 \%$ of patients, respectively). Particular attention should be paid to hypokalaemia (serum potassium $<3.5 \mathrm{mEq} / \mathrm{L}$ ), which was seen, but was relatively rare, namely $3 \%$ of patients in the OPAK-HK trial and $6 \%$ outpatients in the AMETHYST-DN trial.[26]

Currently ongoing trials are recruiting patients with kidney 
dysfunction, including those with end stage kidney disease (Use of Patiromer to Transition Chronic Kidney Disease Patients With Hyperkalemia to a Plant-rich Diet, ClinicalTrials.gov Identifier: NCT03183778 and The Effects of Patiromer on Serum Potassium Level and Gut Microbiome of ESRD Patients With Hyperkalemia, ClinicalTrials.gov Identifier: NCT03326583, respectively).

\section{Conclusions}

Hyperkalaemia is common in patients with HF, particularly in elderly and in subjects with comorbidities (CKD and DM). Hyperkalaemia may limit the introduction/up-titration of lifesaving drugs blocking the RAAS. Recently, new drugs (zirconium cyclosilicate and patiromer) have been approved to treat hyperkalaemia. They are safe and effective in lowering potassium level in HF patients. Clinical studies of patiromer and ZS-9 have demonstrated a dose-dependent potassium-lowering effect for both agents. They may be helpful in optimising RAASi therapies in patients with hyperkalaemia. However, their benefits on longterm outcomes should be further evaluated in larger and longer randomised clinical trials concentrating on clinical outcome events. Also, drug-drug interactions have been demonstrated with patiromer but not yet investigated with ZS-9. Although there are some concerns about hypomagnesaemia and positive calcium balance from patiromer, and sodium overload from ZS-9, both agents have been shown to be well tolerated. Upcoming clinical trials should aim to investigate whether these new treatments for hyperkalaemia could plausibly improve clinical outcomes in specific patient groups that are prone to arrhythmias (e.g. patients with pre-existing cardiovascular disease, or patients with advanced CKD. Despite these gaps of knowledge, in light of their pharmacological properties and available evidence collected so far, patiromer and ZS-9 are promising agents in the management of hyperkalaemia in cardiovascular patients. The treatment and prevention of significant hyperkalaemia has received increasing attention in recent times.[27]

\section{Declarations of interest}

The authors declare no conflict of interest.

\section{Acknowledgements}

The authors state that they abide by the authors' responsibilities and ethical publishing guidelines of the International Cardiovascular Forum Journal.[28]

\section{References}

1. Llubani R, Vukadinović D, Werner C et al. Hyperkalaemia in Heart FailurePathophysiology, Implications and Therapeutic Perspectives. Curr Heart Fail Rep 2018;15(6):390-397

2. Cardiovascular diseases-fact sheet. World Health Organization. http:// www.who.int/mediacentre/factsheets/fs317/en/.

3. Ponikowski P, Voors AA, Anker S et al. 2016 ESC Guidelines for the diagnosis and treatment of acute and chronic heart failure. The Task Force for the diagnosis and treatment of acute and chronic heart failure of the European Society of Cardiology (ESC). Eur Heart J 2016; 37(27):2129-2200.

4. Acker CG, Johnson JP, Palevsky PM, Greenberg A. Hyperkalemia in hospitalized patients. Causes, adequacy of treatment and results of an attempt to improve physician compliance with published therapy guidelines. Arch Intern Med 1998; 158(8):917-24.

5. Fleet JL, Shariff SZ, Gandhi S, Weir MA, Jain AK, Garg AX. Validity of the International Classification of Diseases 10 th revision code for hyperkalaemia in elderly patients at presentation to an emergency department and at hospital admission. BMJ Open. 2012; 2(6): pii: e002011.

6. Einhorn LM, Zhan M, Hsu VD, et al. The frequency of hyperkalemia and its significance in chronic kidney disease. Arch Intern Med 2009; 169(12):115662.

7. Drawz PE, Babineau DC, Rahman M. Metabolic complications in elderly adults with chronic kidney disease. J Am Geriatr Soc 2012; 60(2):310-5.
8. Kovesdy CP. Updates in hyperkalemia: Outcomes and therapeutic strategies. Rev Endocr Metab Disord 2017;18(1):41-47.

9. Weir MR, Rolfe M. Potassium homeostasis and renin-angiotensinaldosterone system inhibitors. Clin J Am Soc Nephrol. 2010; 5:531-548.

10. Susantitaphong P, Sewaralthahab K, Balk EM, et al. Efficacy and safety of combined vs. single renin-angiotensin-aldosterone system blockade in chronic kidney disease: a meta-analysis. Am J Hypertens. 2013; 26:424-441.

11. Desai A. Hyperkalaemia associated with inhibitors of the reninangiotensin aldosterone system: balancing risk and benefit. Circulation 2008;118(16):1609-11.

12. Palmer BF. Managing hyperkalemia caused by inhibitors of the renin angiotensin-aldosterone system. N Engl J Med 2004; 351:585-92.

13. Khder Y, Shi V, McMurray JV, Lefkowitz MP. Sacubitril/Valsartan (LCZ696) in Heart Failure. Hand Exp Pharmacol 2017; 243:133-165.

14. Palmer BF, Clegg DJ. Diagnosis and treatment of hyperkalemia. Cleve Clin J Med 2017;84(12):934-942.

15. Fordjour $\mathrm{KN}$, Walton T, Doran JJ. Management of hyperkalemia in hospitalized patients. Am J Med Sci 2014; 347(2):93-100.

16. Emmett M, Hootkins RE, Fine KD, Santa Ana CA, Porter JL, Fordtran JS. Effect of three laxatives and a cation exchange resin on fecal sodium and potassium excretion. Gastroenterology 1995; 108(3):752-60.

17. Scherr L, Ogden DA, Mead AW, Spritz N, Rubin AL. Management of hyperkalemia with a cation-exchange resin. N Engl J Med 1961; 264:115-9.

18. Harel Z, Harel S, Shah PS, et al. Gastrointestinal adverse events with sodium polystyrene sulfonate (kayexalate) use: a systematic review. Am J Med 2013; 126(3):264.e9-24.

19. Nepal M, Bucaloiu ID, Norfolk ER. Hypernatremia in a patient treated with sodium polystyrene sulfonate. Int J Nephrol Renovasc Dis 2010; 3:141-3.

20. Kosiborod M, Rasmussen HS, Lavin P, et al. Effect of sodium zirconium cyclosilicate on potassium lowering for 28 days among outpatients with hyperkalemia: the HARMONIZE randomized clinical trial. JAMA 2014; 312(21):2223-33.

21. Anker SD, Kosiborod M, Zannad F et al. Maintenance of serum potassium with sodium zirconium cyclosilicate (ZS-9) in heart failure patients: results from a phase 3 randomized, double-blind, placebo-controlled trial. Eur $J$ Heart Fail 2015;17(10):1050-1056.

22 Pitt B, Bakris GL, Bushinsky DA, et al. Effect of patiromer on reducing serum potassium and preventing recurrent hyperkalaemia in patients with heart failure and chronic kidney disease on RAAS inhibitors. Eur J Heart Fail 2015; 17(10):1057-65.

23. Pitt B, Anker SD, Bushinsky DA, et al. Evaluation of the efficacy and safety of RLY5016, a polymeric potassium binder, in a double-blind, placebocontrolled study in patients with chronic heart failure (the PEARL-HF trial). Eur Heart J 2011; 32(7):820-8.

24. Buysee JM, Huang IZ, Pitt B. PEARL-HF: prevention of hyperkalemia in patients with heart failure using a novel polymeric potassium binder, RLY5016. Future Cardiol 2012; 8(1):17-28.

25. Weir MR, Bakris GL, Bushinsky DA, et al.; OPAK-HK Investigators. Patiromer in patients with kidney disease and hyperkalemia receiving RAAS inhibitors. N Engl J Med 2015; 372(3):211-221.

26. Pitt B, Bakris GL, Weir MR, et al. Long-term effects of patiromer for hyperkalaemia treatment in patients with mild heart failure and diabetic nephropathy on angiotensin-converting enzymes/angiotensin receptor blockers: results from AMETHYST-DN. ESC Heart Fail 2018; 5(4):592-602.

27. Rosano GMC, Tamargo J, Kjeldsen KP et al (2018). Expert consensus document on the management of hyperkalaemia in patients with cardiovascular disease treated with renin angiotensin aldosterone system inhibitors: coordinated by the Working Group on Cardiovascular Pharmacotherapy of the European Society of Cardiology. Eur Heart $J$ Cardiovasc Pharmacother 4: 180-8.

28. Shewan LG, Coats AJS, Henein MY. Authors' Responsibilities and Ethical Publishing. International Cardiovascular Forum Journal 2018;13:3-4, DOI: 10.17987/icfj.v13i0.525. 